\title{
PENURUNAN NYERI PERSALINAN DENGAN KOMPRES HANGAT DAN MASSAGE EFFLEURAGE
}

\section{Decrease of Labor Pain with Warm Compress and Effleurage Massage}

\author{
Stang Abdul Rahman ${ }^{1}$, Ary Handayani ${ }^{2}$, Sumarni ${ }^{3}$, Anwar Mallongi ${ }^{4}$ \\ ${ }^{1}$ Bagian Biostatistik Fakultas Kesehatan Masyarakat Universitas Hasanuddin \\ ${ }^{2}$ Akademi Kebidanan Minasa Upa Makassar \\ ${ }^{3}$ Sekolah Tinggi Ilmu Kesehatan Mega Rezky Makassar \\ ${ }^{4}$ Bagian Kesehatan Lingkungan Fakultas Kesehatan Masyarakat Universitas Hasanuddin \\ (stangbios@gmail.com)
}

\begin{abstract}
ABSTRAK
Nyeri persalinan memiliki derajat yang paling tinggi diantara rasa nyeri yang lain sehingga banyak perempuan yang belum siap memiliki anak karena membayangkan rasa sakit yang akan dialami saat melahirkan. Tujuan penelitian mengetahui perbandingan nyeri persalinan sebelum dan setelah diberikan kompres hangat dan massage effleurage. Penelitian ini adalah penelitian pre-eksperimen dengan rancangan One-Group PretestPosttest Design. Populasi penelitian adalah semua ibu bersalin yang datang ke ruang bersalin Puskesmas Plus Bara-Baraya Makassar dalam setahun terakhir sebanyak 504 orang dan besar sampel 22 orang. Pengambilan sampel menggunakan simple random sampling. Analisis data menggunakan komputer program SPSS dengan uji Wilcoxon Signed Ranks Test. Hasil penelitian menunjukkan adanya penurunan nyeri persalinan, dengan rata-rata nyeri sebelum intervensi mean=7,00 setelah intervensi menjadi mean=4,14. Hasil uji statistik diperoleh nilai $\mathrm{p}=0,000$ yang berarti $\mathrm{p}<0,05$, dengan demikian dapat disimpulan bahwa ada penrunan secara signifikan nyeri persalinan pada primipara setelah diberikan kompres hangat dan massage effleurage selama kala satu persalinan. Kata kunci : Persalinan, hangat, effleurage

ABSTRACT

Labor pain is one of the most painful of pains that cause many women to not be ready to have children because they imagine the pain that they will experience during child birth. The purpose of this research is to determine the comparison of labor pain before and after administration of a warm compress and effleurage massage. This research is a pre-experiment study with a one-group pretest-posttest design. The study population was mothers in labor who came to the delivery room in Bara-Baraya Plus Community Health Center in Makassar in the last year, which were 504 people and a sample size of 22 people. Sampling was conducted using simple random sampling. Data analysis was conducted using SPSS with Wilcoxon Signed Ranks Test. The results showed a decrease in labor pain, in which the average pain before intervention was 7,00 and after the intervention became 4,14. Statistical test results obtained a value of $p=0,000$ which means the $p<0,05$. Thus, it can be concluded that there is a significant reduction in labor pain in primiparas after being given a warm compress and effleurage massage during the first stage of labor.
\end{abstract}

Keywords : Labor, warm, effleurage 


\section{PENDAHULUAN}

Persalinan dapat dikatakan sebagai puncak dari serangkaian latihan pendahuluan sehingga akhirnya tercapai keadaan optimal kesehatan ibu dan janin untuk meyongsong proses kelahiran bayi. ${ }^{1}$ Persalinan berhubungan dengan dua jenis nyeri yang berbeda. Pertama berasal dari otot rahim saat otot itu berkontraksi. Oleh karena merupakan organ internal, maka nyeri yang timbul saat otot rahim ini berkontraksi disebut nyeri viceral (nyeri yang bersifat tumpul, rasa terbakar dan samar batas lokasinya). Sama seperti nyeri visceral lainnya, nyeri yang timbul tidak dapat ditentukan dengan tepat lokasinya (pin-pointed). Jenis nyeri yang kedua timbul pada saat mendekati kelahiran. ${ }^{2}$

Sebenarnya rasa nyeri diperlukan untuk mengenali adanya kontraksi uterus selama proses persalinan, tetapi kadang rasa nyeri tersebut bisa menimbulkan akibat patologis yang dirasakan terus menerus, ditambah rasa cemas dan ketakutan yang dialami ibu bersalin. Hal ini dapat mengakibatkan keletihan sehingga mengakibatkan penurunan kontraksi uterus dan proses persalinan pun berlangsung lebih lama. Persalinan yang lama (prolonged labor) dapat membahayakan ibu dan janin. ${ }^{2}$ Partus lama merupakan penyumbang kematian ibu terendah, akan tetapi jumlahnya mengalami peningkatan dari tahun 2010 sebesar $1,0 \%$, tahun 2011 sebesar $1,1 \%$ dan tahun 2012 sebesar $1,8 \%{ }^{3}$

Penelitian yang dilakukan oleh Zahra Ghanbari, et al. mendapatkan hasil sebesar 35\% dari responden memilih melahirkan dengan cara sectio caesaria (SC) karena takut pada nyeri persalinan. ${ }^{4}$ Nyeri persalinan merupakan sumber yang paling signifikan dari ketidaknyamanan saat melahirkan, sehingga dapat menghasilkan tingkat rasa sakit yang sering melebihi batas ketahanan fisik. $^{5}$ Selama persalinan itu sendiri, ada variabel lain yang membuat persepsi nyeri yang dirasakan setiap wanita adalah unik, yaitu frekuensi kontraksi, ukuran dan posisi bayi, lama persalinan, kebebasan bergerak, derajat keletihan maupun kecemasan, merasa sendiri versus mendapat dukungan dan besarnya rasa percaya diri dan kesiapan. ${ }^{6}$

Umumnya, cara menghilangkan sakit persalinan dapat dilakukan secara medis dan non medis. Cara menghilangkan sakit persalinan secara medis adalah dengan pemberian obat-obat anal- gesia yang disuntikkan melalui infuse intravena, melalui inhalasi saluran pernapasan, atau dengan memblokade saraf yang menghantarkan rasa sakit. Tindakan ini sudah banyak digunakan di beberapa rumah sakit di Indonesia untuk membantu ibu dalam proses melahirkan. ${ }^{7}$

Metode non-medis yang dapat digunakan untuk nyeri persalinan adalah teknik kompres hangat. Teknik kompres hangat selama proses persalinan dapat mempertahankan komponen sistem vaskuler dalam keadaan vasodilatasi sehingga sirkulasi darah ke otot panggul menjadi homeostatis serta dapat mengurangi kecemasan dan ketakutan serta beradapatasi dengan nyeri selama proses persalinan. ${ }^{8}$ Teknik non medis lainnya adalah massage atau pijat. Pijat cara lembut membantu ibu merasa lebih segar, rileks dan nyaman selama persalinan. Dalam persalinan, pijat juga membuat ibu merasa lebih dekat dengan orang yang merawatnya. Sentuhan seseorang yang peduli dan ingin menolong merupakan sumber kekuatan saat ibu sakit, lelah atau takut. ${ }^{9}$

Menurut Profil Kesehatan Indonesia tahun 2014, jumlah ibu bersalin untuk wilayah Sulawesi Selatan sebanyak 175.792 orang. ${ }^{10}$ Hasil studi pendahuluan pada bulan Maret 2016 di Ruang Bersalin Puskesmas Plus Bara-Baraya Makassar diperoleh data ibu bersalin selama bulan Januari sampai dengan Desember 2015 sebanyak 504 orang, jadi rata-rata persalinan adalah 42 orang setiap bulan. Saat ini terdapat 1 dari 2 pasien primipara sedang dalam persalinan kala I. Para ibu primipara ini menyatakan tidak tahan dengan nyeri yang dirasakan terutama pada kala I. Ibu merasakan nyeri dibagian perut, pinggang, punggung dan menjalar ketulang belakang. Di Ruang bersalin Puskesmas Plus Bara-Baraya tersebut belum memberikan terapi non-farmakologis seperti kompres hangat dan massage effleurage kepada ibu saat melahirkan, sehingga ibu terus merasakan nyeri saat melahirkan. Penelitian ini bertujuan mengetahui perbandingan nyeri persalinan sebelum dan setelah diberikan kompres hangat dan massage effleurage pada primipara.

\section{BAHAN DAN METODE}

Jenis penelitian yang digunakan adalah pre eksperimen dengan rancangan One-Group Pre test-Post test Design. ${ }^{11}$ Penelitian ini dilak- 
Tabel 1. Karakteristik Responden

\begin{tabular}{lcc}
\hline \multicolumn{1}{c}{ Karakteristik } & n & \% \\
\hline Usia & & \\
$\quad<20$ tahun & 3 & 13.6 \\
$\quad$ 20-35 tahun & 19 & 86.4 \\
Pendidikan & & \\
$\quad$ Tamat SMP & 4 & 18.2 \\
$\quad$ Tamat SMA & 18 & 81.8 \\
Pekerjaan & & \\
$\quad$ IRT & 19 & 86.36 \\
$\quad$ Pegawai swasta & 2 & 9.09 \\
$\quad$ Wiraswasta & 1 & 4.54 \\
\hline
\end{tabular}

sanakan di Kota Makassar pada bulan Juni-Juli 2016. Populasi penelitian adalah semua ibu bersalin yang datang ke ruang bersalin Puskesmas Plus Bara-Baraya Makassar berjumlah 504 orang. Sampel penelitian ini adalah ibu primipara. Penarikan sampel menggunakan random acak sederhana dengan besar sampel 22 orang. Pengumpulan data dilakukan dengan wawancara menggunakan kuesioner. Nyeri persalinan diukur menggunakan alat pengukur skala nyeri Visual Analoque Scale. Analisis data yang dilakukan adalah univariat dan bivariat dengan uji Wilcoxon Signed Ranks Test. ${ }^{12}$ Penyajian data dalam bentuk tabel disertai narasi.

\section{HASIL}

Sebagian besar subyek berusia 20-35 tahun $(86,4 \%)$, dengan tingkat pendidikan tamat SMP $(18,2 \%)$, tamat SMA $(81,8 \%)$, mata pencaharian subyek $86,36 \%$ bekerja sebagai IRT, pegawai swasta $(9,09 \%)$ dan wiraswasta $(4,54 \%)$ (Tabel 1). Adapun pada pengukuran pre-test skala nyeri pada kelompok intervensi, yang mengalami nyeri sedang sebanyak $15(68,18 \%)$ dan yang mengalami nyeri berat sebanyak $7(31,82 \%)$ subyek, sedangkan pada pengukuran nyeri post test, yang mengalami nyeri ringan sebanyak $4(18,18 \%)$ dan yang mengalami nyeri sedang sebanyak 18 $(81,82 \%)$ subyek serta tidak ada subyek yang mengalami nyeri berat. Hal ini menunjukkan adanya penurunan rata-rata skala nyeri sebesar 2,86 (Ta- bel 2).

Pada penilaian pre-test, skala nyeri terendah adalah 6 dan skala nyeri tertinggi adalah 8 dengan rata-rata skala nyeri adalah 7,0. Pada penilaian post-test, skala nyeri terendah adalah 3 dan skala nyeri tertinggi adalah 6 dengan ratarata skala nyeri 4,14 , hal ini menunjukkan adanya penurunan nyeri sebesar 2,86 (Tabel 3). Hasil uji statistik yang membandingkan nyeri persalinan antara pre-test dan post-test diperoleh nilai $\mathrm{p}=0,000(\mathrm{p}<0,05)$, hal ini berarti ada perbedaan nyeri persalinan yang signifikan sebelum dan sesudah diberikan kompres hangat dan massage effleurage (Tabel 4).

\section{PEMBAHASAN}

Terapi kompres hangat merupakan suatu tindakan yang dilakukan dengan memberikan kompres hangat untuk memenuhi kebutuhan rasa nyaman, mengurangi atau membebaskan nyeri, mengurangi atau mencegah terjadinya spasme otot dan memberikan rasa hangat. Kompres panas juga memperlancar sirkulasi darah; mengurangi rasa sakit; memberi rasa hangat, nyaman dan tenang pada klien; memperlancar pengeluaran eksudat serta merangsang peristaltik usus.

Massage effleurage merupakan suatu metode non farmakologi. Massage adalah salah satu teknik menghilangkan rasa sakit yang paling efektif. Massage effleurage merupakan manipulasi sistematis jaringan lunak terutama otot, tendon dan kulit. Hal ini juga berguna untuk melemaskan otot-otot yang tegang dan menimbulkan relaksasi. Masssage effleurage juga dapat memperkuat hubungan antara perawat dan pasien dan pada gilirannya dapat menciptakan suasana terhadap perbaikan kesehatan dan penyembuhan

Hasil penelitian yang diperoleh menunjukkan bahwa terdapat penurunan rata-rata skala nyeri persalinan setelah diberikan kompres hangat dan masssage effleurage. Hasil uji statistik memperlihatkan adanya perbedaan rata-rata skala

Tabel 2. Tingkat Nyeri Pretest dan Posttest pada Kelompok Intervensi

\begin{tabular}{lcccc}
\hline $\begin{array}{c}\text { Intensitas nyeri } \\
\text { (Intervensi) }\end{array}$ & $\mathbf{n}$ & $\begin{array}{c}\text { Nyeri ringan } \\
\mathbf{n}(\%)\end{array}$ & $\begin{array}{c}\text { Nyeri sedang } \\
\mathbf{n}(\%)\end{array}$ & $\begin{array}{c}\text { Nyeri berat } \\
\mathbf{n}(\%)\end{array}$ \\
\hline Pre test & 22 & - & $15(68.18)$ & $7(31.82)$ \\
Post test & 22 & $4(18,18)$ & $18(81,82)$ & - \\
\hline
\end{tabular}


Tabel 3. Distribusi Responden Berdasarkan Skala Nyeri Pre test dan Post test

\begin{tabular}{cccccc}
\hline Intensitas Nyeri & $\mathbf{n}$ & Range & Minimum & Maximum & Mean \\
\hline Pre test & 22 & 2 & 6 & 8 & 7.00 \\
Post test & 22 & 3 & 3 & 6 & $\mathbf{4 . 1 4}$ \\
\hline
\end{tabular}

Tabel 4. Analisis Nyeri Sebelum dan Setelah Dilakukan Intervensi dengan Uji Wilcoxon

\begin{tabular}{ccccccc}
\hline & & $\mathbf{n}$ & Mean Rank & Sum of Ranks & Z & p \\
\hline & Negative Ranks & $22^{\mathrm{a}}$ & 11.50 & 253.00 & & \\
Post test-Pre test & Positive Ranks & $0^{\mathrm{b}}$ & 0.00 & 0.00 & -4.195 & 0.000 \\
& Ties & $0^{\mathrm{c}}$ & & & & \\
& Total & 22 & & & & \\
\hline
\end{tabular}

nyeri persalinan sebelum dan setelah diberikan terapi. Penurunan skala nyeri yang terjadi disebabkan karena pada pemberian kompres hangat dapat memperlancar sirkulasi darah, mengurangi rasa sakit, memberi rasa hangat, nyaman dan tenang. Pemberian massage bertujuan menghasilkan relaksasi atau meningkatkan sirkulasi atau aliran oksigen dan nutrien juga menghilangkan ketegangan fisik maupun emosional.

Penelitian ini sejalan dengan penelitian Manurung, dkk., yang menyatakan bahwa hasil uji regresi linear ganda membuktikan hubungan ketiga variabel terapi kompres dan skala nyeri persalinan kala satu fase aktif sebelum periode intervensi dengan skala nyeri persalinan sesudah periode intervensi menunjukkan rentang hubungan yang sangat erat $(\mathrm{R}=0,901)$. Skala nyeri sesudah periode intervensi menurun sebesar 2,07 poin setiap responden diterapi dengan kompres hangat, meningkat sebesar 0,71 setiap peningkatan skala nyeri persalinan jika tidak di kontrol. Kesimpulan dari penelitian ini bahwa pemberian terapi kompres hangat sangat efektif dalam menurunkan nyeri persalinan. ${ }^{13}$

Ahmed, dkk., tahun 2014 mendapatkan hasil bahwa paparan air/mandi air hangat dapat meredakan rasa sakit dan kecemasan dalam kala 1 persalinan. Subjek yang diberikan terapi mandi hangat memiliki rasa sakit dan kecemasan dengan tingkat signifikan lebih rendah $(\mathrm{p}=0,011$ dan $\mathrm{p}=0,018$ ) dibandingkan dengan kelompok kontrol. ${ }^{5}$

Hasil penelitian Mutia, dkk., tahun 2015 mendapatkan hasil bahwa terdapat perbedaan rerata derajat nyeri setelah kompres panas dan dingin dengan nilai $\mathrm{p}=0,003$. Terdapat perbedaan selisih derajat nyeri kompres panas dan dingin $\mathrm{p}=0,001$. Terdapat pengaruh pemberian kompres panas dan dingin terhadap penurunan nyeri persalinan. ${ }^{14} \mathrm{Ha}-$ sil penelitian Tarigan tahun 2015 mendapatkan hasil bahwa terdapat perbedaan intensitas nyeri sebelum dan sesudah dilakukan teknik effluarage dengan nilai $p=0,003$. Teknik effluarage mempunyai pengaruh yang positif dengan penurunan tingkat nyeri yaitu jika pemberian teknik effluarage sering dilakukan maka tingkat nyeri dapat berkurang. ${ }^{15}$

\section{KESIMPULAN DAN SARAN}

Terdapat penurunan skala nyeri persalinan sebelum dan setelah terapi pada kelompok intervensi. Sebelum terapi, skala nyeri terendah adalah 6 dan skala nyeri tertinggi adalah 8 dengan ratarata skala nyeri adalah 7,00. Sedangkan setelah terapi, skala nyeri terendah adalah 3 dan skala nyeri tertinggi adalah 6 dengan rata-rata skala nyeri adalah 4,14 . Ada pengaruh kompres hangat dan massage effleurage terhadap penurunan nyeri persalinan pada primipara selama kala satu persalinan setelah dilakukan intervensi dengan nilai $\mathrm{p}=0,000$. Kompres hangat dan massage effleurage dapat menurunan nyeri persalinan sebesar 2,86. Saran bagi pihak Puskesmas Plus Bara-Baraya Makassar khususnya tenaga kesehatan yang bertugas di ruang persalinan agar dapat menerapkan penatalaksanaan terapi kompres hangat dan massage effleurage kepada ibu primipara selama kala satu persalinan sebanyak masing-masing dua kali pemberian atau sesuai dengan keluhan ibu agar rasa nyeri yang dirasakan ibu dapat berkurang.

\section{DAFTAR PUSTAKA}

1. Manuaba. Pengantar Kuliah Obstetri. Jakarta: 
EGC; 2007.

2. Yesie Aprillia. Hipnostetri :Rileks, Nyaman dan Aman Saat Hamil dan Melahirkan. Jakarta: Gagas Medi; 2010.

3. Kementerian Kesehatan RI.Pusat Data dan Informasi. Jakarta : Kementerian Kesehatan RI; 2013.

4. Zahra Ghanbari, Rana Shokouhmand, Hekimeh Khatoon Asadi, Shirin Naghizadeh, Fatemeh Chupani. Assessing the Relative Contribution of Causes Leading to Cesarean Section among who had Referred to Shahid Madani Clinic in Marand City. International Jounal of Womens Health and Reproduction Cciences. [Online Journal] 2014. [diakses 10 Januari 2016]. Available at: http://www.ijwhr. net.

5. Fatma Ahmed Abo Romia and Azza Fouad Mohammed El-Adham. Effect of Warm Showering on Labor Pain During the First Stage of Labor. International Jornal of Advanced Research. 2014;2(5):438-442.

6. Simkin Penny, Janet Whalley, Ann Keppler. Panduan Lengkap Kehamilan, Melahirkan dan Bayi. Yogyakarta : Arcan ; 2010.

7. Putri Ika Damayanti dkk Buku Ajar Asuhan Kebidanan Komprehensif pada Ibu Bersalin dan Bayi Baru Lahir. Yogyakarta : Deepublish; 2014.
8. Price, A. Sylvia and Wilson, M. L.Patofisiologi : Konsep Klinis, Proses-proses Penyakit. Jakarta : EGC; 2005.

9. Danuatmaja Bonny, Meiliasari Mila. Persalinan Normal Tanpa Rasa Sakit. Jakarta : Puspa Swara; 2008.

10. Kementerian Kesehatan Republik Indonesia. Profil Kesehatan Indonesia. Jakarta : Kementerian Kesehatan Republik Indonesia; 2014

11. Budiman. Penelitian Kesehatan. Bandung: Refika Aditama; 2011.

12. Stang. Cara Praktis Penentuan Uji Statistik dalam Penelitian Kesehatan dan Kedokteran. Jakarta : Mitra Wacana Mediak; 2014.

13. Manurung S, Ani N, Tri Riana Li, Ii Soleha, Suryati, Hi, Pengaruh Tehnik Pemberian Kompres Hangat terhadap Perubahan Skala Nyeri Persalinan Pada Klien Primigravida. Jurnal Health Quality. 2013;4(1):1 - 8.

14. Mutia F., Masrul, Iryani Detty. Pengaruh Kompres Panas dan Dingin terhadap Penurunan Nyeri Kala I Fase Aktif Persalinan Fisiologis Ibu Primipara. Jurnal Kesehatan Andalas. [Online Journal] 2015. [diakses 1 Januari 2016]. Available at: http://jurnal.fk.unand.ac.id.

15. Tarigan HN. Pengaruh Teknik Effluarage terhadap Intensitas Nyeri pada Ibu Persalinan Kala I . Nestra-Jurnal.2015; 4(4) : 33-46. 